\title{
MEMÓRIAS DE LA QUEMA. O CIRUJEO EM BUENOS AIRES TRINTA ANOS DEPOIS
}

Mariano Daniel Perelman

\section{Introdução}

Na cidade de Buenos Aires existe uma grande quantidade de pessoas que vive da separação do lixo, em busca de materiais que possam ser reciclados, seja no nível doméstico ou no industrial. São conhecidos como cirujas ou catadores (cartoneros).

A presença na cidade do que hoje conhecemos como cirujas pode ser rastreada pelo menos até 1860, quando aparecem pela primeira vez nas "Memorias Municipales" (documentos oficiais). A atividade, no entanto, adquiriu visibilidade recentemente. As transformações sociais ocorridas nos anos 90 (levando o desemprego a índices históricos ${ }^{1}$ ) e a desvalorização da moeda nacional no início de $2002^{2}$ contribuíram para a aparição massiva de cirujas pelas ruas da cidade de Buenos Aires. ${ }^{3}$ Durante os primeiros anos da década seguinte, o desemprego manteve seus altos índices e milhares de pessoas - muitas delas com trajetórias de trabalho formal - recorreram ao cirujeo* como forma de ganhar a vida.

Se bem que não existam cifras oficiais sobre a quantidade de cirujas que realizam a atividade na cidade, e as estimativas sejam por demais desiguais, resulta inegável o aumento que ela teve nos últimos anos. Tal incremento produziu nessa atividade mudanças tanto quantitativas quanto qualitativas: aumenta a quantidade de pessoas que aderiram ao cirujeo, ${ }^{4}$ mudam as modalidades em que esta prática se apresentava nos cenários anteriores e potencializa-se o papel do circuito informal na recuperação de resíduos (Paiva \& Perelman 2008). Para dimensionar a magnitude que esta prática

* [N.T.] Cirujeo corresponde em português à atividade do "catador de lixo". Mantenho o termo na língua de origem por constituir uma categoria com flexões verbais e nominais que não são de uso em português 
foi adquirindo, basta dizer que, segundo estudo realizado pela Dirección General de Políticas de Reciclado Urbano (DGPRU), no ano de 2006, foram recuperados, por essa via, $97 \%$ dos dejetos gerados diariamente na cidade (Pardo et al. 2006:23).

Em outro trabalho (Perelman 2007), estabelecemos a distinção entre os novos cirujas (aqueles que começaram a cirujear recentemente, tendo sido trabalhadores formais no passado) e os cirujas estruturais (os que sempre o foram). Para estes últimos, o cirujeo supõe a forma "habitual" de vida, e costumam reconhecê-lo como algo dado, assumido e estabelecido, já que faz parte de suas vidas há vários anos e há várias gerações. Pelo contrário, para os primeiros, ter começado a realizar a atividade é vivido como uma forte ruptura nas trajetórias de trabalho. ${ }^{5}$

Neste contexto, com o desemprego em níveis históricos, a ausência de políticas de reciclagem e de regulamentação, as fortes transformações no mundo do trabalho - quando rapidamente o cirujeo se torna visível na cidade e se transforma em uma questão socialmente problematizada — os novos cirujas (os novos pobres) vão receber maior atenção dos pesquisadores. ${ }^{6}$

No entanto, o importante grupo dos estruturais, que começou a cirujear antes da última ditadura militar (1976-1983) — quando foi fechado o vazadouro de resíduos conhecido como La Quema, onde se realizava o cirujeo e morava a maioria dos catadores - tem recebido menos atenção dos pesquisadores.

Neste artigo, focalizamos este grupo para entender como se realizava então essa atividade tendo em vista as percepções atuais. Nós nos centramos na vida em La Quema, nos sentidos que a atividade adquiriu a partir dos relatos tomados trinta anos depois, ou seja, lançamos indagações sobre narrações mediadas pelo tempo e pelos processos descritos, em que a atividade se viu nutrida de novos sujeitos e foi objeto de outros discursos, incentivados pela ditadura militar e consolidados na democracia. Ao indagar sobre uma atividade marginal realizada por sujeitos que deveriam fazer parte do mercado de trabalho, em uma Argentina onde "não trabalhava quem não queria", o caso do cirujeo serve como porta para analisar como se constrói memória social e pessoal. ${ }^{7}$ Ao mesmo tempo, nos permite problematizar e desnaturalizar as percepções dos sujeitos que cirujean (e dos investigadores) sobre a atividade atualmente.

Entre 2002 e 2007, realizamos entrevistas em profundidade com cirujas que desempenharam a atividade antes da ditadura e que continuaram nela durante a democracia. Esses relatos foram complementados com entrevistas feitas com outros sujeitos e com a análise de fontes documentais, com o objetivo de constatar e contrastar, pôr em destaque ou problematizar a visão 
dos entrevistados. Nesse mesmo período, fizemos entrevistas com sujeitos que começaram a cirujear em fins da década de 1990, buscando diferenças e semelhanças em relação aos sentidos que os demais outorgavam a esta atividade.

O argumento com o qual trabalhamos aqui é que os cirujas históricos constroem um passado contraposto às formas presentes, produzidas em um contexto bem distinto. $O$ fato de não serem os únicos que realizam a atividade lhes permite tornar mais confortável um passado de forte marginalização social. A análise dessas memórias possibilita, ao mesmo tempo, que nos concentremos nos discursos - cambiantes - em torno de ser e de ter sido trabalhador na Argentina, mostrando como a memória é um processo ativo que tenta dar coerência às práticas passadas. Desta forma, o interesse em analisar as visões dos cirujas estruturais nos leva a abordar arestas medulares de um dos mecanismos identitários centrais da Argentina do século XX: o trabalho.

\section{Ser ciruja na Argentina do pleno emprego. A vida em La Quema}

A Argentina anterior ao último regime de fato (1976) foi considerada uma sociedade próxima do pleno emprego, na qual a segurança e os direitos sociais, a saúde, as relações sociais, a participação política e grande parte da identidade social estavam ligados ao trabalho. ${ }^{8}$ A participação no mercado de trabalho significou o "modo legítimo" de acesso ao consumo para reproduzir a própria vida. Desta representação, adveio uma maneira legítima de pertencimento, o que supôs certas obrigações e também direitos legais e específicos (Grassi 2003:83). O trabalho formal foi, na Argentina, uma das principais formas de integração social e um vetor central das identidades coletivas.

Isto foi possível graças às altas taxas de ocupação que caracterizaram o mercado argentino até meados da década de 1970. Neste modelo, o Estado de meados do século XX institui-se como um ator ativo na política econômica, alinhando suas ações em direção à conformação de uma ordem que colocava o trabalho e a categoria de trabalhador no centro da cena, tanto no que se refere à construção legal quanto identitária do sujeito. Assim, os direitos sociais foram se configurando como direitos do trabalho e ficaram indissoluvelmente ligados a este. A condição socioocupacional e a capacidade de aporte ao sistema foram os fatores determinantes do seguro social (obras sociais e previdência) das pessoas.

Uma vez imposta a obrigação de "trabalhar para viver", o trabalho aparece mais como um direito em si mesmo do que uma condição doadora 
de direitos. Assim é que se foi constituindo na memória social a ideia de que "não trabalha quem não quer".

Nesta situação, a centralidade do status de "ocupados" resultou na exclusão dos que faziam parte desse mercado de trabalho informal ao acesso aos direitos sociais, já que a contingência da "falta de postos de trabalho" não esteve contemplada, assim como tampouco esteve a possibilidade de que o salário não cobrisse as necessidades do trabalhador. Assim, grande parte da população (ativa) deu "lugar à persistência de um significativo setor informal na economia, parte do qual gerava rendas baixas para aqueles que ali estavam ocupados" (Beccaria \& Lopez 1997:86). Em face da construção de um sujeito de direito em relação ao trabalho, as políticas assistenciais tiveram como objetivo "o amparo pelo Estado das pessoas que por causas fortuitas ou acidentais se viram privadas dos meios indispensáveis de vida e que, carecendo deles, se encontraram incapacitadas de forma definitiva para obtê-los" (Alayón 1980:36). Os cirujas que viviam e trabalhavam em La Quema eram estes sujeitos que não encontravam trabalho, mesmo estando em idade e condição de fazê-lo.

Recordemos brevemente a formação de La Quema de Bajo Flores. Em fins do século XIX, pela falta de higiene e de condições de salubridade, coloca-se em questão o sistema de "queima ao ar livre", ${ }^{9}$ fechando-se assim o local onde esta se realizava e adotando o sistema de incineração em fornos domésticos e industriais. Este método não dava conta da eliminação total dos resíduos, motivo pelo qual, aos poucos, foram gerados diferentes lixões a céu aberto. Um deles, situado no Bajo Flores e conhecido como "La Quema del Bajo Flores", nascido na década de 1920, com o passar dos anos converteu-se em um imenso lixão a céu aberto, onde os cirujas encontraram seu meio e lugar de vida (ver Figura 1, à direita, para a localização de La Quema). Nos seus arredores, instalaram-se galpões, depósitos e fábricas que compravam e vendiam os dejetos que os cirujas coletavam. Ao mesmo tempo, esses estabelecimentos moldaram as formas operativas de La Quema e conferiram à zona sul da cidade uma fisionomia particular (Paiva \& Perelman 2010). Paralelamente, criaram-se as villas de emergencia, ${ }^{10}$ habitadas majoritariamente por migrantes do interior em busca de uma vida melhor que, paradoxalmente, terminaram nos lixões de Buenos Aires.

Durante a pesquisa, encontramos poucas fontes, assim como pesquisas em torno da vida em La Quema. Isto pode ser lido como um silêncio, um dos tantos que existem na história dos setores marginais, que não se encaixavam na narrativa da cidade, capital da Argentina moderna e do pleno emprego. ${ }^{11}$

Nesse ponto, as memórias dos sujeitos que ali viveram e/ou trabalharam tornam-se cruciais. Os sujeitos narram suas vidas a partir do presente, tentan- 


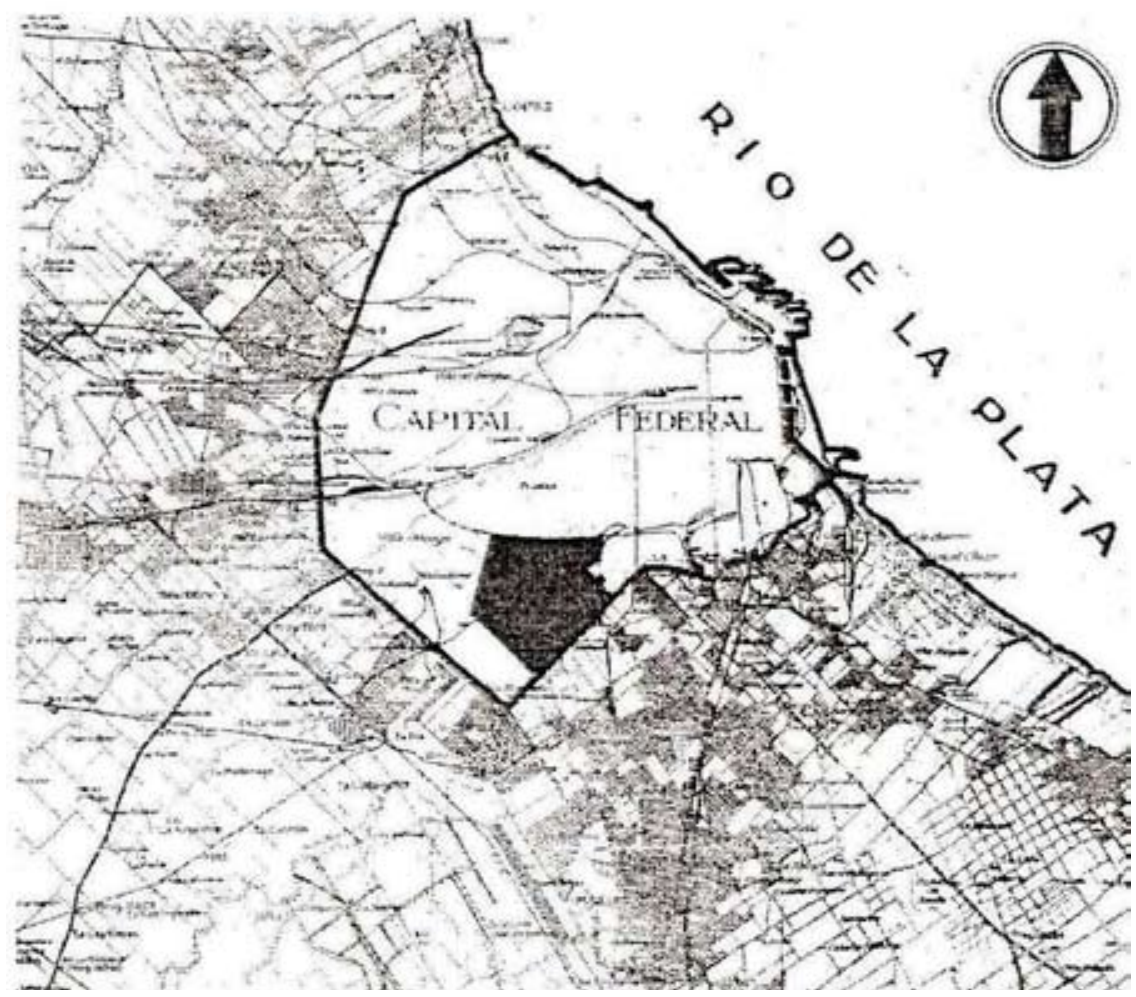

Fonte - Boletín de Obras Sanitarias de La Nación, 1941.

do conferir coerência às suas trajetórias. Nos relatos dos cirujas estruturais, produzidos trinta anos depois, é possível constatar uma série de marcas nas quais se lê a tentativa de dar coerência àquele passado não tão confortável. Nas entrevistas, os sujeitos se contradizem e surgem visões contrapostas. Neste sentido, para nosso trabalho, optamos por adotar a precaução de Guber (2007:22) ao propor que

[...] é próprio daqueles que analisam os fenômenos ligados à memória social observarem tendências uniformizantes entre o presente e um passado nem sempre confortável para obter versões convenientes. Em vez de interpretar esses desacertos e divergências entre passado e presente como sinais do interesse e da manipulação, proponho tratá-los como parte de um padrão de historicidade que oferece distintas composições de sentido que afetam as posições daqueles que recordam, modelando a produção de seus contextos presentes. 
Como desenvolvemos em outro trabalho (Perelman 2008), a vida em La Quema era dura e perigosa. A topografia fazia com que entre as montanhas de lixo se formassem grandes valas cheias de água contaminada. Havia o cheiro putrefato e a fumaça constante, os enxames de moscas, os objetos cortantes, os focos de doenças e o fato de trabalhar sobre altíssimos montes de resíduos. Mas a estas condições devemos agregar, sobretudo, a configuração social (Elias 1985), que pode ser entendida como uma configuração de territórios de violência (Daich, Pita \& Sirimarco 2007). ${ }^{12}$ Se La Quema aparecia, em primeira instância, como um lugar aberto, já que não tinha um limite fixo e estabelecido, as relações que nela se estabeleciam a tornavam um lugar de fronteiras - fronteiras criadas pela estruturação de relações sociais e pelos imaginários construídos, fazendo com que essas linhas fossem difíceis de ultrapassar. Não são necessários grandes muros, cercas elétricas, seguranças armados para diferenciar espaços e temporalidades. Somente uma rua dividia La Quema do barrio, ${ }^{13}$ mas cruzá-la significava adentrar no território onde a violência era um capital central.

O território estava controlado por "capangas", que formavam bandos para controlar zonas. Segundo Valentín, um dos tantos cirujas que viveu em La Quema, capanga "é aquele que maneja com a força e à força os grupos, e se autodenomina chefe". Diante da minha pergunta sobre como era feito, responde: "com violência, dando exemplos de violência [...] Uma briga, uma confusão, te davam um tiro, uma facada. E não era só ele, se você brigava, você já sabia que os outros vinham, porque estavam todos, tinham que dar o exemplo. A força se impunha".

Em um artigo publicado na revista Atlántida, de 1965, pode-se ler:

"Fincar bandeira" pode resultar um significativo avanço hierárquico em La Quema [...] A insígnia é também símbolo de posse territorial. Ele, e somente ele, tem o direito de cavar dentro do perímetro estipulado ao redor da bandeira. O domínio territorial é conquistado através de obscuras lutas e intrigas que mobilizam a transumante família dos cirujas. No melhor dos casos, a zona própria é obtida mediante o uso direto da força [...] Em La Quema, as disputas são cotidianas e constantes. As brigas poucas vezes ocorrem com socos. Tanto o rastelo quanto afiadas barras de aço guardadas na cintura são as armas mais comuns. Também tem quem use revólver. Os "caciques" os carregam como símbolos de autoridade e para amedrontar aqueles que tentem "bancar o esperto" (Petcoff 1965:22-27).

Coco, um ciruja que começou a trabalhar em La Quema em 1975, quando tinha 16 anos, explicava que "tinha bandos que te tiravam à força se você estivesse só, ou seja, se não tivesse ninguém pra te respaldar, vinham 
dois ou três e saqueavam tua mercadoria". Se você não fazia parte do bando dele, "te tiravam à força". Juan, outro dos tantos que ali moraram, lembra que "quando você conseguia reunir muita coisa, mas estava só, você já sabia que eles iam te tirar as coisas na marra".

Em poucas palavras, para trabalhar em La Quema era preciso gerar, com a presença, uma relação de cotidianidade e conhecimento mútuo. Sobretudo, era necessário mostrar coragem para defender o que se tinha coletado. Juntar-se em bandos era tão necessário quanto demonstrar valor no momento necessário.

La Quema era um mundo moral, um lugar praticado, operacionalizado, especificado mediante ações de sujeitos históricos (De Certeau 1996). Diferentemente do que acontecia com o resto dos vizinhos dos bairros onde se localizava La Quema (Villa Soldati \& Villa Lugano), nos relatos dos cirujas, esse não-lugar era transformado em um espaço. ${ }^{14}$ Juan Carlos relembra que "estar em La Quema era como estar em minha casa, com isto te digo tudo. A gente comia, catava as coisas, trazia dinheiro, era um mundo de gente. A gente a chamava de fábrica a céu aberto". A mesma ideia é expressa por José, que ainda hoje diz com orgulho "eu sou quemero", fazendo referência ao sentido de pertencimento que tem hoje ter vivido e trabalhado em La Quema.

La Quema era um território físico, mas também uma rede de relações tanto de amizade e afinidade como de rivalidade (e inimizade). Estas redes foram configurando imaginários, criando espaços dentro e fora de La Quema, percursos que se transformaram nos mapas construídos a partir dessas relações. Com isto não queremos dizer que exista uma única sensação ou conceitualização quanto aos processos sociais. No entanto, podemos sim propor que existam algumas semelhanças, regras tácitas de comportamento, moralidades dominantes em cada grupo social que configuram de maneira determinada o universo do imaginável.

Além do descrito, devemos acrescentar as contínuas razzias policiais e a estigmatização social com a qual os moradores de La Quema deveriam conviver. ${ }^{15}$ Entre os entrevistados existe o forte consenso de que "La Quema era um mundo de excesso", onde "o mais forte ficava com o melhor, e o fraco ficava relegado às coisas de menor valor [...] mas tinha que enfrentar também a violência verbal e física do resto", conta um deles. Outro se lembra que "tudo era marginal, sempre gente fora da lei, ou fugindo, ou que gostava da vida fácil, álcool ou tinha decidido viver de forma violenta".

Se todos os entrevistados dão conta do lugar da violência, de que se tratava de um mundo marginal, de que eram "todos marginais", "todos delinquentes", "malfeitores" e estavam ali porque "não havia outra opção", nenhum deles se inclui nestas classificações. 
Como dissemos, a maior parte dos que aí estavam como cirujas eram pessoas em condições de trabalhar, mas que não conseguiam emprego. A explicação que os entrevistados encontram, a maneira pela qual tentam dar sentido e se afiguram perante tal situação que, como certa vez me disse um deles, "lhe coube" viver, é uma das interrogações que merecem ser analisadas e que nos permitem compreender a maneira que os imaginários em torno da cambiante categoria de trabalhador é internalizada pelos sujeitos. Por sua vez, nos permite entender como a memória, enquanto processo ativo, vai dando sentido aos processos sociais.

Nas entrevistas, as causas para a entrada e a permanência na atividade em La Quema são desiguais. Alguns sustentam que era por decisão, por dinheiro. Juan Carlos diz:

Eu trabalhei 25 anos na Comisión Municipal de la Vivienda. Eu trabalhava de segunda a sexta, e sábado e domingo minha paixão era cirujear. O que eu tirava no sábado e domingo tirava em um mês na Comisión de la Vivienda. Imagina, como eu não ia querer continuar? E bem, depois fiquei em La Quema, me casei, juntei meu dinheiro para fazer minha festa, na igreja, no civil, paguei minha roupa, paguei minha festa, tudo, tudo do meu bolso, graças à ciruja. Criei meus filhos.

Muitos deles terminaram ali por não conseguir trabalho. Coco conta:

Minha questão é que quando vim de Misiones eu tinha 16 anos, e tinha o problema dos documentos. Por causa do trabalho. Na minha casa me diziam que eu tinha que sair porque tinha que pagar luz, gás, tudo isso. E só tinha um salário, que era o do meu padrasto. Então, me diziam que era preciso ajudar, que ele pagava tudo. E eu sem trabalho, sem documento, sem nada [...] então, chegou um rapaz e disse "eu te levo pra trabalhar comigo, se você quiser". E naquela época não te contratavam em lugar nenhum, e menos ainda sem conhecimento, eu venho da província de Misiones. Trabalhava no campo, limpava o terreno, colhia, tudo isso. "Eu posso te ajudar" [...] "tá bom" — eu disse "vamos tentar". E viemos pra cá. [...] E entramos para catar esses metais que eu não conhecia. Lá na província colhíamos milho, tabaco, se plantava. E foi o que consegui.

Apesar das diferentes visões sobre o porquê de estarem ali, na maioria dos testemunhos surgem algumas semelhanças. Quase todos tinham tido algum contato prévio com a tarefa. Se à primeira vista muitos deles parecem ter "caído" em La Quema sem conhecimento anterior da ativi- 
dade, tanto pelos imaginários que existiam em torno dela quanto pela configuração interna do referido local, esta possibilidade parece distante. Desta forma, para além de serem "desocupados" — como os descreve um relatório da década de $1940^{16}$ — a partir das trajetórias, das motivações, das redes sociais, é possível rastrear certa continuidade familiar em relação ao cirujeo. ${ }^{17}$ Cabe destacar que as entrevistas foram realizadas com pessoas que ainda hoje continuam ligadas à atividade. Também é importante mencionar que a maioria dos entrevistados tinha entre 40 e 60 anos. Todas estas variáveis são fatores a serem levados em conta no que se refere às suas trajetórias e às conceitualizações que fazem de suas próprias vidas.

\section{Ditadura, transformações e desemprego}

Com o golpe de Estado de 24 de março de 1976, além do início da implementação das políticas neoliberais ${ }_{1}^{18}$ começa na cidade de Buenos Aires uma forte política urbana com o objetivo de transformá-la numa cidade de elite. ${ }^{19}$ Como desenvolvemos em outro trabalho (Cosacov et al. 2008), parte das políticas de fragmentação instauradas pelo governo militar consistiu nas tentativas de erradicação de amplos setores populares na cidade. Nesse contexto, o General de Brigada Osvaldo Cacciattore levou adiante uma série de medidas que tendiam a modificar seu mapa social, enquadradas em um discurso que tratava a problemática social como uma questão de ordenamento urbano e limpeza da cidade. Operando com a ideia de que a cidade deveria ser o lugar de residência de "gente decente", a "vitrine do país" (Oszlak 1991), as políticas adotadas tiveram consequências sobre a distribuição e a localização espacial da população, gerando um deslocamento físico dos setores populares.

As políticas implementadas nesses anos consistiam em medidas que tendiam a regulamentar o que a ditadura concebia como um desenvolvimento urbano "caótico" e "descontrolado" (Torres 1993) pela ausência de regulamentação e controle. Assim, subjaz a ideia de ordenamento do espaço e sobretudo de "limpeza" da cidade (Clichevsky 1986). Desta forma, reafirmam-se valores como ordem, higiene, beleza e bem-estar, mas apenas para aqueles que são definidos como cidadãos que merecem viver nela, negando e excluindo os setores populares. As declarações de quem, nesse momento, era o titular da Comisión Municipal de Vivienda, Guillermo del Cioppo, durante o governo do General de Brigada Osvaldo Cacciatore, condensam esta concepção: 
É preciso definir uma política de qualidade para os habitantes [...] nestes últimos anos, vimos integrar-se à nossa geografia essa população marginal da qual lhe falava, de muito baixo nível de trabalho. Nós somente pretendemos que vivam em nossa cidade aqueles que estão preparados culturalmente para viver nela [...] Concretamente: viver em Buenos Aires não é para qualquer um, mas para aquele que mereça, para aquele que aceite as pautas de uma vida comunitária agradável e eficiente. Devemos ter uma cidade melhor para gente melhor [...] O problema foi tratado de forma cirúrgica e em tempo recorde. Produzimos a explosão das villas de emergência [...] erradicamos em três anos e meio 100.000 villeros (Revista Competencia, 191, 1980).

Somado a este marco político-ideológico, as políticas da ditadura militar vinculadas à cidade encontravam também sua ancoragem nas discussões e nas novas noções que circulavam nesses anos no âmbito do urbanismo em nível mundial. ${ }^{20}$

Se a ditadura militar arrasou com as correntes que propugnavam a participação ativa da população, não rompeu com as tendências principais da modernização desenvolvimentista que implicava importantes projetos arquitetônicos induzidos pelo Estado. Inclusive os aprofundou com a abertura a capitais estrangeiros - já iniciado na década de sessenta — e a obtenção de créditos de organismos internacionais para grandes projetos. Também incorporou algumas das novas noções que surgiam em um momento em que se questionava o papel do planejamento e se afirmava a necessidade de incorporar outras dimensões, tais como "ambiente".

É nesse contexto que deve ser situada a criação do CEAMSE (organismo metropolitano encarregado da gestão de um cinturão ecológico), os novos "espaços verdes", junto com as reformas das praças de bairros e uma primeira zona de proteção patrimonial no centro histórico - todos temas de "última geração", inscritos em uma cidade imaginada para a elite (Novick 2003). ${ }^{21}$

Como parte desse processo, La Quema foi fechada e seus habitantes desalojados. Um novo sistema de gestão de resíduos foi posto em andamento e, a partir de então, o lixo começou a ser enterrado na província de Buenos Aires. Assim, os cirujas assistiram ao desaparecimento do seu local e do seu meio de vida. A atividade foi proibida e a forma de jogar o lixo foi fortemente pautada.

No início de 1977, os governos da Província e da Municipalidade de Buenos Aires assinaram o convênio de criação deste novo sistema. Estabeleceu-se que se reservariam dois lugares que seriam nivelados mediante a técnica do "aterro sanitário" e recuperados para o uso da população (uma faixa ao longo do rio La Plata entre Riachuelo e a cidade de La Plata; e outro 
na bacia do rio Reconquista). Além disso, decidiu-se pela criação de uma empresa que deveria projetar, executar e fiscalizar a deposição final dos resíduos. Buscava-se, desta forma, uma solução para dois problemas (ou ao menos era assim colocado): por um lado, se dotaria a área metropolitana de espaços verdes suficientes para a população estimada para o ano 2000; por outro, tentava-se pôr fim ao problema dos resíduos domiciliares e industriais mediante um sistema econômico e mais higiênico que La Quema. Foram criadas três estações de transferência, para as quais os resíduos ainda hoje são levados pelos caminhões de coleta. Nesse lugar, os resíduos são transferidos mediante um dispositivo hidráulico para veículos especiais de 22 toneladas de capacidade, que levam o "lixo" ao seu lugar de deposição final. Desta forma, começou-se a exportar lixo da Capital Federal para a Província de Buenos Aires, uma nova expressão das políticas impulsionadas pelo General Cacciattore para tentar transformar a cidade em uma zona "exclusiva".

As medidas tomadas em relação aos resíduos não terminam aqui. O governo municipal, a partir de vários decretos, regulamentou o sistema de coleta e a conduta dos portenhos. ${ }^{22}$ O Decreto n. 33.581 proibiu jogar ou manter qualquer tipo de lixo, desperdícios, água já utilizada ou restos domésticos na via pública, em calçadas, ruas, terrenos baldios ou casas abandonadas. Regulamentou o uso de recipientes destinados a conter os resíduos domiciliares para sua posterior coleta e, para tal, regularizou o uso de bolsas plásticas. Estabeleceu que a coleta diária, porta a porta, de resíduos domiciliares por parte da Municipalidade seria total nos edifícios destinados à moradia, e também nos de uso comercial, industrial ou institucional. Em seu artigo sexto, o decreto estabelecia:

Proíbe-se a seleção, remoção, coleta, aquisição, venda, transporte, armazenamento ou manipulação de todo tipo de resíduos domiciliares que se encontrem na via pública para sua retirada por parte do serviço de coleta; ficam compreendidos na presente proibição a entrega e/ou a comercialização de resíduos alimentícios, qualquer que seja sua procedência.

Um ano mais tarde proibiu-se em todo o âmbito da Capital Federal a descarga de lixo a céu aberto (Ord. $\mathrm{n}^{\circ} 34.523 / 78$ ). Em 1982, por último, mediante o decreto $\mathrm{n}^{\circ} 613$, dispôs-se que as bolsas de resíduos domiciliares fossem depositadas sobre calçadas, de domingo a sexta, a partir das $20 \mathrm{~h}$.

Com a criação do CEAMSE, os cirujas tiveram de compreender que a "mercadoria" já não lhes pertencia, mas era agora propriedade das empresas 
de coleta, e que o lugar para onde ela deveria ser levada era o CEAMSE. Juan Carlos lembra que "na época dos militares, te pegavam [...] te levavam, te batiam, te jogavam no rio, na água podre, te cortavam o cabelo com vidro, te faziam infinidades de coisas. Como se você fosse um extremista. E não! Você era um ciruja". Conjuntamente com uma repressão explícita, uma das práticas habituais dos agentes estatais era a de levá-los ao local onde os dejetos seriam compactados, obrigando-os a formar uma fila e a jogar o "lixo". Esta era a nova ordem das coisas. Um deles conta que "MANLIBA ${ }^{23}$ fazia operações com a polícia [...] não perseguiam aqueles que juntavam o lixo com as mãos, mas aqueles que tinham carro; eles apreendiam a mercadoria e registravam a ocorrência".

A partir de então, a atividade começou a mudar de fisionomia. Os carros tracionados a cavalo ou à mão começaram a circular pela cidade em busca de um lixo que agora estava espalhado pela metrópole (Paiva 2008). Mas como dissemos, a atividade só adquiriu mesmo visibilidade já avançada a década de 1990, quando a partir da conjugação de diversos fatores — falta de emprego, desocupação crescente, disponibilidade de resíduos nas ruas da cidade e demanda de elementos recicláveis por parte das empresas - a coleta informal de resíduos converteu-se em uma estratégia de sobrevivência para muitas famílias da Área Metropolitana de Buenos Aires. Agora, novamente, mudam as modalidades que esta atividade exibia tradicionalmente (Perelman 2007a). Desde então, as formas usuais de coleta são duas: apalpar as bolsas de lixo depositadas nas calçadas, abri-las, extrair os resíduos de valor e tornar a fechá-las, ou estabelecer contatos - vizinhos, comerciantes, porteiros de edifícios — que lhes reservam os resíduos. Por esta razão para não perder os contatos - o catador tem rotas estáveis que devem ser realizadas em horários fixos, já que o contato entrega os resíduos em um horário preestabelecido que o ciruja deve cumprir.

A segunda modalidade que se estabeleceu durante o ano de 2001 foi o traslado em caminhão. Sobre eles pode-se dizer que existem três tipos de caminhões: o caminhão de frete, o caminhão balança e o caminhão empresa. Na cidade, recolhem resíduos para revender como papelão, papel, plásticos, vidros e metais, enquanto subsidiariamente recolhem os alimentos que os comerciantes entregam e a roupa que os vizinhos dão. Tais elementos servem para consumo da família. Após a coleta, os catadores realizam uma primeira classificação dos dejetos em algum espaço reservado para isso em suas casas. São classificados segundo o tipo e vendidos a depósitos compradores desses materiais, de acordo com a frequência que marca as necessidades do lar: diária, semanal ou quinzenalmente. 


\section{Memórias de La Quema}

Michael Pollak (2006) recorda que a memória proporciona um marco e pontos de referências. A memória é situada a partir de um trabalho de enquadramento que não se constitui arbitrariamente, que tem seus limites, e que deve satisfazer certas exigências de justificação. Este enquadramento, evidentemente, não se dá de uma vez e para sempre. Em certos contextos, as outras memórias - às quais Pollak se refere como subterrâneas e que podem passar despercebidas pela sociedade em geral em função dessa memória coletiva "mais legítima" - vão surgir na cena pública. Nos anos 90, aquelas histórias não contadas, esses não-ditos, surgiram como lembranças de um passado que só agora - a partir do aumento de cirujas e do crescimento do desemprego - pode ser contado. Por exemplo, foi em 2006, quase 30 anos depois, que Valentín relatou a mim, mas também à sua esposa e filhos, pela primeira vez, seu passado em La Quema. O gênero narrativo da vivência sempre importante, como nos lembra Tonkin (1995) - era épico.

Antes da década de 70, viver em La Quema significava não fazer parte da sociedade, do coletivo que legitimamente vendia sua força de trabalho. Era estar à margem desse espaço onde, como recordam Danani e Grassi (2008), se configuram as condições de participação na distribuição dos benefícios produzidos e/ou acumulados; conformam-se as condições de acesso ao consumo e, em boa medida, também se escreve um capítulo fundamental da produção de identidade, reconhecimento e subjetividade.

As transformações levadas adiante pela última ditadura militar (1976-1983), que tenderam à implementação do modelo neoliberal e à desarticulação da sociedade argentina, tiveram sem dúvida influência nas formas de conceber o trabalho, que foi se configurando - diferentemente das décadas anteriores - como um bem escasso em uma sociedade "em crise". Aquele Estado que se inclinava a garantir e a fomentar a categoria de trabalhador, tornou-se assistencial, por um lado; e defensor do trabalho a qualquer custo (emprego cada vez mais precário e vulnerável), por outro. As práticas dos sujeitos dão conta desta mesma necessidade de trabalho enquanto forma digna de vida, e elas se articulam de maneira contraditória com uma série de relações, agora pensadas como direitos.

Se as formas de lembrar e de esquecer são individuais, não se pode negar que esses processos estão enquadrados a partir de diferentes pertencimentos (como gênero, classe, grupo social, família), e que não ocorreram em indivíduos isolados, mas em sujeitos. Por sua vez, como disse Waldman (2006:32), memória e esquecimento estão em um "frágil equilíbrio de forças ligado aos cambiantes sentidos e interpretações do passado, que sempre, 
em última instância, respondem a interrogações do presente e a projeções do futuro".

É nos novos cirujas que aquele imaginário sobre o trabalho - ou para ser mais preciso, sobre certos tipos de atividades — vai se reacomodar à nova situação traumática. Se, no início, ser ciruja é negado, o que faz com que se escondam e se envergonhem do que fazem (Perelman 2010), e as novas condições de vida aparecem como um silêncio, quando começam a falar surgem justificativas que se referem àquele enquadramento dos processos sociais e à tentativa de tornar mais aceitável uma realidade que até pouco tempo não imaginavam. Os entrevistados costumam dizer que se é ciruja quando não se pode ser outra coisa. Mas este não ser outra coisa enquadra-se nos limites do moralmente realizável, nessa trama de relações fixada nas memórias dos grupos sociais. Geralmente, os cirujas contrapõem a atividade ao roubo. Esta distinção não é casual, e com ela demarcam os limites do que é bom e do que é mal: fazem-no para enfatizar que sua atividade é (apesar de tudo) algo de valor, mas também para se oporem ao discurso que os colocou naquele lugar. A construção da necessidade de ser trabalhador, de ganhar a vida via mercado de trabalho continua permeando os imaginários e influenciando as ações dos sujeitos.

Diferentemente deste grupo, os cirujas estruturais tem outra história para lembrar e contar. Neste contexto, as lembranças de La Quema são ressignificadas, não são mais os referidos marginais, mas se tornam os legítimos cirujas. Aqui e agora, aquelas relações violentas aparecem como coragem, como conhecimento sobre a forma com que se deve realizar a tarefa. E aquelas brigas internas e relações de inimizades vão se esfumando para conduzir a um reconhecimento geral a todos os moradores do local.

Certa vez, um dos cirujas históricos - que trabalhou em La Quema e atualmente percorre as ruas da cidade com um carrinho de mão - me mostrou uma folha onde tinha escrito uma série de "regras" de como se deveria fazer a tarefa, como se comportar, porque "os de agora não têm códigos, deixam tudo sujo e depois colocam a culpa em nós, estão bêbados e mal vestidos". Por "nós" referia-se aos que, segundo ele, realmente sabem como se faz a atividade, que têm "códigos" que os legitimam. A legitimidade passa por terem vivido em La Quema, serem os originais, os reais cirujas, os que sempre o foram. Isto conferiria uma base de conhecimentos e de regras tácitas entre eles. No entanto, assim como nem todos os cirujas estruturais se comportam "adequadamente", tampouco os novos cirujas o fazem de maneira inadequada. Não obstante, os estruturais tentam culpar os novos pelo processo de estigmatização que o cirujeo sofreu conforme foi crescendo a atividade. ${ }^{24}$

Aqui também encontramos uma distinção entre um grupo estabelecido e um novo (Elias \& Scotson 2000). Em seu estudo sobre uma pequena 
comunidade inglesa, Elias e Scotson dão conta de como, dentro da classe trabalhadora, são geradas relações de estigmatização. Assim afirmam: “a reputação dos 'estabelecidos' era engrandecida por um pequeníssimo número de famílias 'socialmente superiores', enquanto a dos 'outsiders' era decisivamente marcada pelas atividades de seu setor mais baixo" (2000:56). Para gerar esse processo identitário, esse orgulho, começam a aparecer as lembranças, que se bem não sejam tão confortáveis como dizia Guber (2007), "confortabilizam-se": o lixo era melhor; as fábricas jogavam de tudo, roupa nova, coisas em bom estado, comida ${ }_{i}^{25}$ matadouros, abatedouros, caminhões inteiros eram jogados; tudo o que tinha sido "apreendido, mas em bom estado" ia parar em La Quema, esclarece Coco.

No discurso de Pedro, a Argentina do pleno emprego surge como contraditória. Ele contava que se sentia marginalizado e que não fazia parte dela. Mas, ao mesmo tempo, se sentia parte:

Os tempos mudaram. Já não é como antes; antes tinha uma Argentina aceitável, [da qual] se podia dizer que era um país que podia competir com os melhores países do mundo [...] e a produção que se fazia na Argentina, essa indústria estava a mil. Sobrava. As indústrias, que indústrias! Em San Martín, em Caseros, fábricas que agora estão vazias [...] agora estão fechadas. Tudo isso era cheio, imagina, tudo isso gerando lixo. E todos trabalhando.

Um pouco românticos, um pouco realistas, recordam que viviam bem do lixo: "voltavas pra casa com dinheiro" e "podias comprar o que querias", "não faltava nada pra família, e pagavas tudo trabalhando lá dentro [em La Quema]". "Mais produção, mais consumo e mais lixo", diz Valentín.

Essas novas condições faziam com que a vida em La Quema fosse revestida de uma nova cor, mais brilhante, que não fala de um passado de exclusão social, mas de possuidores das práticas legítimas, às quais hoje milhares de pessoas recorrem para poder sobreviver. Se antes se fazia porque se era marginal, diante da quantidade de pessoas que na atualidade a realizam, agora é "normal" e esta normalidade se torna anacrônica.

Então, aparece um "nós", os quemeros, um orgulho construído com as memórias ressignificadas: se antes quemeros eram ladrões, alcoólatras ou arruaceiros, hoje são os que tinham a coragem para fazê-lo. O "eu sou quemero", enquanto elemento identificatório, nos fala de um sentido de pertencimento que se constrói a partir de uma memória do grupo contraposta à dos novos cirujas. Seguindo o estabelecido por Pollak, os atuais processos são parte do enquadramento das memórias de La Quema. 


\section{À guisa de conclusão. Do purgatório ao paraíso}

Uma das questões a resgatar é o que faz com que hoje venha à tona e se quebre o silêncio em torno da vida em La Quema. Não acreditamos que se deva somente ao interesse crescente dos pesquisadores em relação ao cirujeo (que por certo não tem sido muito no caso de La Quema), mas também ao fato de que as condições sociais atuais, às quais nos referimos neste trabalho, geraram certa possibilidade, menos traumática, de rememorar as experiências vividas pelos moradores de La Quema. Aquelas memórias subterrâneas, silenciadas social e pessoalmente, são memórias reconstruídas, com um novo sentido - memória e esquecimentos que aparecem como silêncios nas histórias pessoais e coletivas que hoje adquirem um sentido diferente.

O fato, por exemplo, de que os filhos e a esposa de Valentín escutassem pela primeira vez comigo, em 2006, sobre a vida em La Quema demonstra que aquela história, hoje, pode ser contada e ouvida. A possibilidade de poder apelar para o orgulho de ser quemero, contado de maneira gloriosa, vai na mesma direção.

Neste trabalho, analisamos os processos que permitiram essa "confortabilidade", essa possibilidade. Destacamos a aparição massiva de cirujas, quase 30 anos depois do fechamento de La Quema, a visibilidade, a nova intervenção do Estado e a instalação do tema na arena pública, processos que fizeram com que as memórias dos cirujas daquela vida inviável já não mais o sejam. Pelo contrário, permite que se reivindiquem como os "verdadeiros cirujas", como os legítimos, podendo sentir-se orgulhosos disto.

O caso dos cirujas estruturais evidencia que, embora a situação não varie muito para eles, são as rupturas destes outros sujeitos - os novos cirujas - e as mudanças nos imaginários em torno do (poder) ser trabalhador e ganhar "a vida dignamente" 26 que servem como marco de referência para um processo de reidentificação.

Neste contexto, aquele viver em La Quema que significava estar fora do coletivo, dos modos legítimos de venda da força de trabalho, de ser considerado "marginal dentro do marginal" agora é lembrado e entendido de maneira oposta.

Desta forma, o caso do cirujeo dá conta de como as memórias de grupos marginais, inclusive daqueles que a priori aparecem como fora dos marcos de referência (neste caso, o trabalho), ressignificam-se em função de experiências e contextos, e como os sujeitos tentam dar coerência ao seu passado a partir de marcos sociais de enquadramentos. Assim, as memórias coletivas, grupais, por mais marginais que pareçam, estão construídas em relação aos discursos totalizadores, dos quais, a priori, não fazem parte. 
Por último, quero destacar que este artigo propõe uma precaução metodológica àqueles que tentam recuperar os processos sociais a partir de entrevistas, das histórias de vida. Sem subestimar a importância que elas têm como ferramenta para a construção desses processos, e mais ainda quando se trabalha com "grupos marginais", é necessário considerar as memórias em si como parte dos processos sociais.

Recebido em 10 de julho de 2009

Aprovado em 30 de março de 2010

Tradução de Maria José Alfaro Freire

Mariano Perelman é doutorando em antropologia social na Universidad de Buenos Aires (UBA). E-mail: <mdp1980@yahoo.com.ar>

\section{Notas}

${ }^{1}$ De acordo com o INDEC (Instituto Nacional de Estatística e Censos da Argentina), na cidade de Buenos Aires e na Grande Buenos Aires, o desemprego cresceu de $2,4 \%$ em abril de 1975 para 12,6\% no primeiro trimestre de 2006 (chegando a picos de $20,2 \%$ em maio de 1995 e $22 \%$ em 2002); o subemprego, por sua vez, era de $4,7 \%$ em abril de 1975 e de 12,3\% em 2006. Neste ano, 30\% da população vivia abaixo da linha de pobreza, o que representa 22,5\% dos lares. Além disso, 10,3\% de pessoas vivem na indigência (7,1\% do total dos lares). Em relação à desigualdade na renda, os $10 \%$ mais ricos ganhavam 37 vezes mais do que os $10 \%$ mais pobres, enquanto em 1974 essa relação era de 12,3.

${ }^{2}$ Durante quase uma década existiu uma lei que equiparava o valor do peso (moeda local) ao dólar norte-americano.

${ }^{3}$ Além disso, temos que destacar as falências das normatizações que regulavam a gestão dos resíduos sólidos urbanos em todo a área metropolitana de Buenos Aires, e as próprias motivações que tornaram possível que um importante grupo de pessoas tenha visto no cirujeo uma opção válida como forma de sobrevivência. Sobre este tema, ver Perelman (2010b).

${ }^{4}$ Não existem estatísticas anteriores a 2001. Segundo Suárez (2001a), em 2001 havia cerca de 100 mil pessoas vivendo do cirujeo. Uma publicação oficial do Go- 
bierno de la Ciudad de Buenos Aires (GCBA) estabelecia a cifra em 8 mil (Secretaria de Meio Ambiente, 2001). Se seguirmos o argumento de Suárez, pode-se dizer que em 1998 havia menos de 40 mil. Um relatório da Organização Internacional para as Migrações (OIM) e da UNICEF estimava que no ano de 2005 aproximadamente 8.762 pessoas trabalhariam na recuperação de resíduos na cidade de Buenos Aires, das quais mais da metade eram residentes do conurbano bonaerense. Durante os últimos anos, tenho tentado, sem êxito, conseguir cifras oficiais atualizadas. O impacto que a rápida aparição massiva de cirujas teve na opinião pública pode ser apreciado pela importância que a imprensa conferiu ao fenômeno a partir de 2001 (Cf. Perelman 2004).

${ }^{5}$ Cabe destacar que as categorias de novo ciruja e ciruja estrutural não só se referem à "antiguidade" das pessoas naquele trabalho, mas a uma série de valorações e formas de entender o cirujeo, geradas a partir das trajetórias familiares e pessoais. Esta posição permitiu a Schamber (2008) diferenciar, dentro dos cirujas estruturais, os históricos e os recentes.

${ }^{6}$ Nos últimos anos, foi produzida uma série de trabalhos que, a partir de diferentes disciplinas, analisam distintos ângulos da atividade. No entanto, apesar disso, constituiu-se um corpus relativamente homogêneo que esquematicamente dividiremos em dois. Por um lado, os que enfatizam a relação cirujeo e meio ambiente. Entre eles se destacam Schamber (2008); Suárez (1998, 2001b), Paiva (2008), Paiva \& Perelman (2010). O segundo grupo pode ser subdividido em dois: os que veem na atividade uma resposta positiva à crise social (Reynals 2003; Kohes 2005), e os que centram seu argumento nas consequências das políticas neoliberais e na desarticulação do mercado de trabalho (Gorban 2006, 2004; Dimarco 2005; Gutiérrez 2005; Perelman 2004, 2007a).

${ }^{7}$ Recuperamos aqui a conceitualização de Jelin (2002) em relação às memórias coletivas enquanto memórias compartilhadas, superpostas, produto de interações múltiplas, enquadradas em marcos sociais e em relações de poder. Neste sentido, o coletivo é um entretecido de tradições e memórias individuais, socialmente organizadas, estruturadas, dadas por códigos culturais compartilhados. No contexto das relações, algumas "vozes" são mais potentes que outras. Assim entendidas, as memórias coletivas não são algo dado, existem disputas e negociações de sentidos entre distintos atores sociais (incluindo os excluídos e marginalizados) que tentam dar sentido ao passado em cenários diversos. Por sua vez, dizem Jelin e Kaufman (2001:27-28) "a memória, sujeita aos processos individuais e coletivos, é sempre uma relação intersubjetiva, baseada no ato de transmissão e reinterpretação, que requer de outros e outros para recordar: é o suporte grupal o que dá coesão e estrutura à vida: também à memória".

${ }^{8}$ Talvez esta afirmação esteja mais ligada aos imaginários que aos índices reais de ocupação e desocupação. Existem diferenças entre os índices de emprego e os imaginários em torno da situação. Da mesma forma, é possível pensar que não é o mesmo ter emprego e ter boas condições de vida. 
${ }^{9} \mathrm{La}$ Quema começou a funcionar "de fato" em meados de 1860 e foi inaugurada formalmente em 1873. Estava localizada no bairro de Nueva Pompeya, ao sul da cidade. Com a privatização do sistema de coleta, em 1861, a Municipalidad passou a dá-la em concessão para que empresários tratassem o lixo que os carros de limpeza recolhiam. O concessionário deveria realizar a queima logo depois de separar tudo aquilo que pudesse ser comercializado: móveis, garrafas, metais, vidros, ossos, panos, papel etc. A Municipalidad, por sua vez, além de cobrar uma taxa pela concessão, podia fazer uso das cinzas, produto da cremação dos resíduos. Desde 1873, começou a ser utilizado o método inventado um ano antes pelo administrador geral de Limpeza Pública, Ángel Borches, que consistia na "queima ao ar livre": colocava-se o lixo em "grades de ferro, onde era queimado em fogo lento", sem outro tratamento final, além da incineração a céu aberto (Memoria Municipal de 1972).

${ }^{10}$ Em outros países são conhecidas como "favelas" (Brasil), "barriadas" (México), "chabolas" (Espanha), "slum" (nos países de fala inglesa).

${ }^{11}$ Retomamos a ideia de Troulliot (1995) em relação à revolução haitiana. Existem diferentes formas de silenciamento, como podem ser a banalização e o menosprezo de certos fatos e processos.

${ }^{12}$ Recuperamos esta categoria para pensar nosso trabalho. As autoras usam-na para refletir sobre "a face mais violenta" das instituições: desde acionar policial de repressão, coação e ameaça a jovens de bairros "pobres" em Buenos Aires até a falta de atenção nos postos de saúde local. Fazem-no para pensar especialmente a respeito dos territórios "de violência e controle policial". Segundo elas, nos relatos das mulheres desses bairros aparece "uma delimitação das fronteiras [...], já não físicas, mas sociais, que dão conta destas múltiplas relações. Pois, embora exista uma delimitação física que está relacionada aos lugares pelos quais se pode transitar livremente ou não cuja localização depende de uma experiência e de um saber local - existe também, sobre eles, a delimitação de um mapa social" (2007:74-75). É importante fazer uma diferenciação: no trabalho de Daich et al. (2007) as configurações estão construídas em função da violência policial, o que gera relações sociais (territoriais e que constroem uma territorialidade que vai além do espaço físico). Neste sentido, são gerados mapas que marcam tanto distâncias sociais como distâncias estruturais, no sentido dado por Evans Pritchard (1987). No caso de La Quema, a violência mantém status entre os que vivem e trabalham nela, delimitando um território social e físico.

${ }^{13}$ Em outro trabalho, desenvolvemos, a partir do fechamento de La Quema, as fortes diferenças existentes entre seus habitantes e os que viviam dos resíduos, os moradores dos complexos habitacionais e "os vizinhos nobres" de Villa Soldati (Cf. Cosacov, Perelman, Ramos \& Rodriguez 2008).

${ }^{14}$ Em relação à categoria de não-lugar, nós nos remetemos a Augé (2000). Entendemos espaço nos termos de Michel De Certeau (1996).

${ }^{15}$ Segundo Tiscornia (2008:22-23), “as razzias são decisões políticas, armas de um vasto campo ideológico que evoca a guerra e a violência, ao mesmo tempo em 
que impõem disciplina. São parte do arsenal de técnicas policiais cujo sistema de operação é acionado muito mais para instaurar e estender um determinado sentido de ordem e moralidade pública do que para castigar faltas ou delitos. É a presença violenta da autoridade política que ultrapassa - ostensivamente - qualquer limite de direito". Que os cirujas tenham sido objeto de constantes batidas policiais fala da visão que existia sobre essa autoridade em certos âmbitos governamentais.

${ }^{16} \mathrm{O}$ relatório da comissão encarregada de estudar o problema dos lixos em 1942 refere-se a eles como "desocupados" (Cf. Schamber 2008).

${ }^{17}$ Não é o tema deste trabalho, mas é necessário observar que existem processos morais que habilitam a possibilidade do cirujeo como forma legítima de ganhar a vida (Ver Perelman 2010b).

${ }^{18}$ A estrutura social entre 1955 e 1976 poderia ser caracterizada como "heterogênea por cima e homogênea por baixo", produto do desenvolvimento econômico e do jogo de relações de força de políticas particulares da Argentina. Durante esse período, a situação se inverte. Esses dois processos são o corolário de uma política ativa de desaparecimento e terror do governo militar sobre os setores populares que, de forma alguma, foi à toa. A tentativa de unificação por cima desenvolveu-se em um triplo movimento de concentração (centralização do capital, reconversão do aparato produtivo), hegemonia (a tendência predominante do setor financeiro constituiu a forma genérica de articular interesses) e representação (a tentativa do governo militar em representar os interesses dos setores dominantes). A fragmentação por baixo é produto de políticas de desindustrialização, clausura sindical, crescimento do trabalho não-assalariado, divisão da classe trabalhadora, por exemplo, diferenciando salários (Villarreal 1985).

${ }^{19}$ É um discurso recorrente sobre a cidade de Buenos Aires que se reatualiza a partir da construção do outro (Cf. Lacarrieu 2005).

${ }^{20}$ Segundo Hall (1996), nos anos 60, em um contexto mundial de crise paradigmática que afetava os distintos âmbitos da vida social, política e cultural, surgiram três temas essenciais que questionaram radicalmente o planejamento urbano tal como ele era entendido até aquele momento. Discutia-se a figura do "especialista" e o planejamento de "cima para baixo", ao mesmo tempo em que a pobreza crescente mostrava que o planejamento não tinha melhorado as condições de vida das cidades. Finalmente, vivia-se uma desconfiança generalizada sobre como se abordavam os problemas urbanos e sociais. Nesse marco, surgiu - cada vez com mais força e consenso - a necessidade de realizar um planejamento que envolvesse diferentes grupos na elaboração dos objetivos e das metas. Era uma nova forma de planejar que supunha tanto um novo direcionamento de "baixo para cima", como também a importância de dar a conhecer e pôr em discussão os distintos projetos e alternativas antes encerradas nos gabinetes tecnocráticos (Ver Cosacov et al. 2008).

${ }^{21}$ Neste sentido, deve ser destacada a formação do Club de Roma em 1968 e o aparecimento, alguns anos depois, de seu primeiro relatório ("Os limites do 
crescimento") como expressões da crescente preocupação ambiental, junto com a Conferência de Estocolmo (1972) que "consagrou a dimensão planetária do ambientalismo" (Novick 2003:68).

${ }^{22}$ A legislação que prevê como os resíduos sólidos devem ser dispostos dá conta de uma tentativa de disciplinar o conjunto da população.

${ }^{23} \mathrm{~A}$ empresa de coleta que se encarregou das zonas entregues em concessão.

${ }^{24}$ Sobre a estigmatização no cirujeo, consultar Schamber \& Suárez (2007) e Perelman (2008b).

${ }^{25}$ A maioria dos cirujas alimentava-se com o que coletava durante o dia.

${ }^{26}$ Ao analisar as ações estatais e as práticas de mobilização social em torno do desemprego a partir de dois casos (as fábricas recuperadas e as organizações de desocupados), Fernández Álvarez \& Manzano (2007) dão conta de que as categorias de trabalho digno e genuíno resultam centrais "tanto na configuração dos processos de construção identitária como na formação de demandas, mostrando a complexidade que o problema do desemprego assume" (Fernández Álvarez \& Manzano 2007:165). Especificamente em relação ao cirujeo, ver Perelman (2007b, 2007c, 2010b).

\section{Referências bibliográficas}

ALAYÓN, Norberto. 1980. Historia del trabajo social en Argentina. Buenos Aires: Espacio.

AUGÉ, Marc. 2000. Los no lugares. Espacios del anonimato. Una antropología de la sobremodernidad. Barcelona: Gedisa.

BECCARIA, Luis \& LÓPEZ, Nestor. 1997. "El debilitamiento de los mecanismos de integración social". In: L. Beccaria \& López N. (orgs.), Sin trabajo. Las características del desempleo y sus efectos en la sociedad argentina. Buenos Aires: Losada. pp. 85-110.

CLICHEVSKY, Nora. 1986. "Política urbana y mercado de tierra. Buenos Aires 1970-1986". Comunicação apresen- tada no III Seminario sobre Hábitat Popular, México. Mimeo.

COSACOV, Natalia; PERELMAN, Mariano; RAMOS, Julia \& RODRÍGUEZ Florencia. 2008. "'Y por fin un 18 de octubre de 1978...' Pugnas de sentidos a partir del cierre de la Quema en el barrio de Villa Soldati, Ciudad de Buenos Aires". Comunicação apresentada nas V Jornadas Nacionales Espacio, Memoria, Identidad, UNR, Rosario. Mimeo.

DAICH, Deborah; PITA, María \& SIRIMARCO, Mariana. 2007. "Configuración de territorios de violencia y control policial: corporalidades, emociones y relaciones sociales". Cuadernos de Antropología Social, 25:71-88. 
DANANI, Claudia \& GRASSI, Estela. 2008.

"Ni error y ni omisión. El papel de la política de Estado en la producción en las condiciones de vida y de trabajo. El caso del sistema previsional de la Argentina (1993-2008)". In: J. Lindemboim (org.), Trabajo, ingresos y políticas en Argentina. Buenos Aires: EUDEBA. pp. 259-298.

DE CERTEAU, Michel. 1996. La invención de lo cotidiano, 1. Artes de hacer. México: Universidad Iberoamericana.

DIMARCO, Sabina. 2005. Experiencias de autoorganización en cartoneros: un acercamiento a la configuración de vínculos laborales, sociales y políticos en contextos de exclusión social. Relatório final de bolsa, Programa ASDI-CLACSO.

ELIAS, Norbert \& SCOTSON, John. 2000. Os estabelecidos e os outsiders. Rio de Janeiro: Jorge Zahar Editor. .1985. La sociedad cortesana. México: FCE.

EVANS- PRITCHARD, Edward E. 1987. Los Nuer. España: Anagrama.

FERNÁNDEZ ÁLVAREZ, María Inés e MANZANO, Virginia. 2007. "Desempleo, Acción estatal y movilización social en Argentina". Política y Cultura, 27:143-163.

GORBAN, Débora. 2006. "Trabajo y cotidianeidad. El barrio como espacio de trabajo de los cartoneros del Tren Blanco". Trabajo y Sociedad, 5(8), s/p (on-line).

. 2004. "Reflexiones alrededor de los procesos de cambio social en Argentina. El caso de los cartoneros".E-1@ tina, Revista Electrónica de Estudios Latinoamericanos, 8:3-16.

GRASSI, Estela. 2003. Políticas y pro_ blemas sociales en la sociedad neoliberal. La otra década infame (I). Buenos Aires: Espacio.

GUBER, Rosana. 2007. "Los tiempos de ciertas memorias. Algunos usos políticos de la temporalidad en la Argentina". Malestar. Psicoanálisis/ Cultura, 7(6):21-34.

GUTIÉRREZ, Pablo. 2005. "Recuperadores urbanos de materiales reciclables". In: F. Mallimaci \& A. Salvia (orgs.), Los nuevos rostros de la marginalidad. La supervivencia de los desplazados. Buenos Aires: IIGG- UBA/ Biblos. pp. 131-143.

HALL, Peter. 1996. Ciudades del mañana. Historia del urbanismo en el siglo XX. Barcelona: Del Serbal.

JELÍN, Elizabeth. 2002. Los trabajos de la memoria. Madrid: Siglo XXI.

. \& KAUFMAN, Susana. 2001. "Los niveles de la memoria: reconstrucciones del pasado dictatorial argentino". Entrepasados, X(20/21):9-34.

KOHES, Jesica. 2005. "Cuando la ciudadanía apremia. La 'ley cartonera' y la emergencia del cartonero como actor público". In: G. Delamata (org.), Ciudadanía y territorio. Buenos Aires: Espacio. pp 157-186.

LACARRIEU, Monica. 2005. “Nuevas políticas de lugares: recorridos y fronteras entre la utopía y la crisis". In: M. Welch Guerra (org.), Buenos Aires a la deriva. Buenos Aires: Biblos. pp. 366-396.

MEMORIAS de la Municipalidad de la Ciudad de Buenos Aires, 1861.

NOVICK, Alicia. 2003. "Espacios y proyectos. Oposiciones, hegemonías e interrogantes". In: Las dimensiones del Espacio Público. Problemas y proyectos. Buenos Aires: GCBA.

OIM \& UNICEF. 2005. Informe sobre el trabajo infantil en la recuperación y reciclaje de residuos. Buenos Aires: OIM.

OSZLAK, Oscar. 1991. Merecer la ciudad. Los pobres y el derecho al espacio urbano. Buenos Aires: CEDES-HUMANITAS.

PAIVA, Verónica \& PERELMAN, Mariano. 2010. "Aproximación histórica a la recolección formal e informal en la 
ciudad de Buenos Aires: la 'quema' de Parque Patricios (1860-1917) y la del Bajo Flores (1920-1977)". Theomai, 21:134-149.

. 2008. "Recolección y recuperación informal de residuos. La perspectiva de la teoría ambiental y das políticas públicas. Ciudad de Buenos Aires 2001-2007". Cuaderno Urbano, 7:35-54.

PAIVA, Verónica. 2008. Cartoneros y cooperativas de recuperadores. Una mirada sobre la recolección informal de residuos. Área Metropolitana de Buenos Aires, 1999-2007. Buenos Aires: Prometeo.

PARDO, Rubén; CARIBONI, Félix; RISSO, Antonella \& PUGLIESE, Mariela. 2006. Informe sobre el circuito del reciclado en la ciudad autónoma de Buenos Aires. Buenos Aires: Gobierno de la Ciudad de Buenos Aires, Dirección de Políticas de Reciclado Urbano.

PERELMAN, Mariano. 2010. “El cirujeo en la Ciudad de Buenos Aires. Visibilización, estigma y confianza". Revista de Antropología Iberoamericana, 5(1):94-124.

. 2010b. "Construcción de la idea de trabajo digno en cirujas de la ciudad de Buenos Aires". Intersecciones en Antropología, 12. No prelo.

. 2008. "Notas para comprender el cirujeo en la Ciudad de Buenos Aires". Avá, Revista de Antropología, 12:117-135.

. 2008b. "Reflexiones en torno al cirujeo, el trabajo y la verguenza". Actas del IX Congreso Argentino de Antropología, Misiones (formato digital). . 2007. "El cirujeo i̇rebusque o trabajo? Un análisis a partir de las transformaciones de la atividade en la Ciudad de Buenos Aires". In: P. Schamber \& F. Suárez (orgs.), Recicloscopio. Miradas sobre recolectores urbanos de residuos en Amércia Latina. Buenos Aires: UNLa-UNGS- Prometeo. pp. 245-267.

. 2007b. Pobreza urbana, desempleo y nuevos sentidos del (no)trabajo. Cirujas y Movimientos de Trabajadores de Desocupados de la Ciudad de Buenos Aires. Informe final de beca del Programa CLACSO-CROP de Estudios sobre pobreza. Mimeo.

. 2007c. "Theorizing unemployment: toward an argentine anthropology of work". Anthropology of Work Review, 28(1):8-13. . 2004. "Las subjetividades en vidas de cartón. El cirujeo en la Ciudad de Buenos Aires". Trabalho de graduação em Ciências Antropológicas, Universidad de Buenos Aires. Mimeo.

PETCOFF, Emilio. 1965. "El mundo prohibido de los cirujas". Revista Atlántida, 48(1184):21- 27.

POLLAK, Michael. 2006. Memoria, olvido, silencio. La Plata: Ediciones $\mathrm{Al}$ Margen.

PRIMER INFORME de la Comisión de "Estudio de las basuras", Municipalidad de la Capital, 1899.

REYNALS, Cristina. 2003. "De cartoneros a recuperadores urbanos". In: Inés Gonzales Bombal (org.), Respuestas de la sociedad civil a la crisis. Buenos Aires: CEDES.

SCHAMBER, Pablo. 2008. De los desechos a las mercancías. Una etnografía de los cartoneros. Buenos Aires: SB. . \& SUAREZ, Francisco (orgs). 2007. Recicloscopio. Miradas sobre recolectores urbanos de residuos en Amércia Latina. Buenos Aires: UNLa-UNGSPrometeo.

SECRETARIA DE MEDIO AMBIENTE. 2001. Estudio de Calidad de RSU. Buenos Aires: Gobierno de la Ciudad de Buenos Aires.

SUÁREZ, Francisco. 2001a. "El cirujeo se convierte en un trabajo informal". 
Nota del Diario La Nación, 1 de Julio de 2001.

. 2001b. Actores sociales en la gestión de residuos sólidos de los municipios de Malvinas Argentinas y José C. Paz. Tesis de Maestría en Políticas Ambientales y Territoriales, Universidad de Buenos Aires. Mimeo. . 1998. "Que las recojan y arrojen fuera de la Ciudad", Historia de la gestión de los residuos sólidos (las basuras) en Buenos Aires. Documento de trabajo n. 8. Los polvorines: UNGS.

TISCORNIA, Sofía. 2008. Activismo de los derechos humanos y burocracias estatales. El caso Walter Bulacio. Buenos Aires: Editores del Puerto-CELS.

TONKIN, Elizabeth. 1995. Narrating our pasts: the social construction of oral history. Cambridge: Cambridge University Press.

TORRES, Horacio. 1993. El mapa social de Buenos Aires (1940-1990). Serie Difusión, n. 3. Buenos Aires: FADUUBA.

TROULLIOT, Michel-Rolph. 1995. Silencing the past: power and the production of history. Boston: Beacon Press.

VILLARREAL, Juan. 1985. "Los hilos sociales del poder". In: Eduardo Jozami, Pedro Paz \& Juan Villarreal (orgs.), Crisis de la dictadura argentina. Buenos Aires: Siglo XXI Argentina.

WALDMAN M., Gilda. 2006. "La cultura de la memoria. Problemas y reflexiones". Política y Cultura, 26:11-34. 


\section{Resumo}

A partir dos testemunhos e das memórias dos cirujas (catadores de lixo) que viveram e trabalharam em La Quema, Buenos Aires, o artigo recupera os sentidos que esta atividade adquiriu. Ao tomar os relatos registrados trinta anos depois do fechamento de La Quema, em um contexto de crescimento da atividade, argumentamos que os cirujas históricos constroem seu passado contraposto às formas presentes, o que lhes permite tornar mais confortável um passado de forte marginalização social. A análise dessas memórias nos permite focar nos discursos em torno de ser e de ter sido trabalhador na Argentina.

Palavras-chave Catadores, Lixo, Buenos Aires, Memória, Desemprego.

\section{Abstract}

Exploring the testimonies and memories of cirujas (waste pickers) who lived and worked at La Quema, a dump in Buenos Aires, this article reconstructs the meanings acquired by this activity over time. Analyzing these accounts produced some thirty years after the closure of La Quema and in a new social context where the activity has become more commonplace, the text argues that the 'historical' cirujas construct their past in opposition to the present, a process that allows them to make their earlier experience of social marginalization more bearable. The analysis of these memories also enables us to focus on the discourses on being and having been a worker in Argentina.

Key words Cirujas, Waste, Buenos Aires, Memory, Unemployment. 